Goldschmidt 2021 Abstract

https://doi.org/10.7185/gold2021.8003

\section{Ca isotopes as tracers of geothermal gradients in TTG magmas: evidence for hot subduction throughout the Archean}

\author{
MICHAEL A. ANTONELLI ${ }^{1}$, JILLIAN KENDRICK ${ }^{2}$, \\ CHRIS YAKYMCHUK ${ }^{2}$, MARTIN GUITREAU ${ }^{3}$, TUSHAR \\ MITTAL $^{4}$ AND FRÉDÉRIC MOYNIER $^{5}$ \\ ${ }^{1}$ ETH-Zurich \\ ${ }^{2}$ University of Waterloo \\ ${ }^{3}$ Université Clermont Auvergne \\ ${ }^{4}$ Massachusetts Institute of Technology \\ ${ }^{5}$ Université de Paris, Institut de Physique du Globe de Paris, \\ CNRS
}

Presenting Author: michael.antonelli@erdw.ethz.ch

Ca isotopes as tracers of geothermal gradients in TTG magmas: evidence for hot subduction throughout the Archean

Michael A. Antonelli1 ${ }^{1,2}$, Jillian Kendrick $^{3}$, Chris Yakymchuk $^{3}$, Martin Guitreau ${ }^{4}$, Tushar Mittal ${ }^{5}$, Frederic Moynier $^{2}$

\footnotetext{
${ }^{1}$ Institute for Geochemistry and Petrology, Dept. of Earth Sciences, ETH-Zurich, Switzerland.

${ }^{2}$ Institut de Physique du Globe de Paris, Université de Paris, CNRS, UMR 7154, France.

${ }^{3}$ Dept. of Earth and Environmental Sciences, University of Waterloo, Canada.

4 Laboratoire Magmas et Volcans, Université Clermont Auvergne, France.

${ }^{5}$ Dept. of Earth, Planetary and Atmospheric Sciences, MIT,
} USA.

Continents are unique to the Earth and played a significant role in the coevolution of the atmosphere, hydrosphere, and biosphere. There is still much controversy, however, regarding the mechanisms of continental crust formation and the onset of modern style (subduction-driven) plate tectonics. We present stable $\mathrm{Ca}$ isotope and trace-element data from modern and ancient (4.0 to $2.8 \mathrm{Ga}$ ) granitoid samples and phase equilibrium models indicating that $\mathrm{Ca}$ isotope fractionations are dominantly controlled by geothermal gradients. The results require apparent gradients of $500-750^{\circ} \mathrm{C} / \mathrm{GPa}$ for Archean granitoids, as found in many modern (hot) subduction-zones and consistent with the continuous operation of subduction throughout the Archean [1]. Two granitoid samples from the Nuvvuagittuq Supracrustal Belt, Canada, however, cannot be explained only through magmatic processes. Given that these samples have abundant evidence for sediment incorporation [high $\mathrm{A} / \mathrm{CNK}$, high $\delta^{18} \mathrm{O}$, and high $\delta^{30} \mathrm{Si}$ [2]] and that samples in the area have high $\delta^{57} \mathrm{Fe}$ values consistent with sedimentary carbonates [3], their $\mathrm{Ca}$ isotopic signatures were likely inherited from isotopically light $\left(\delta^{44} \mathrm{Ca}<\right.$ $-0.9 \%$, relative to BSE) Ca-rich sediments. These samples ( $>3.8$ $\mathrm{Ga}$ ) predate the oldest known carbonate units preserved in the rock record and lend weight to the idea that carbonate precipitation in early Eoarchean oceans provided an important sink for high atmospheric $\mathrm{CO}_{2}$. These results suggest that subduction-driven plate tectonic processes likely started prior to $\sim 3.8 \mathrm{Ga}$.

[1] Antonelli et al. (resubmitted w/ revisions) Nat. Comms.

[2] Deng et al. (2019) Nat. Geosci. 12

[3] Dauphas et al. (2007) EPSL 254 